\title{
(6) OPEN ACCESS \\ Decreased argyrophilic nucleolar organiser region (AgNOR) expression in Purkinje cells: first signal of neuronal damage in sudden fetal and infant death
}

\author{
Anna M Lavezzi, ${ }^{1}$ Graziella Alfonsi, ${ }^{1}$ Teresa Pusiol, ${ }^{2}$ Luigi Matturri ${ }^{1}$
}

\begin{abstract}
'Department of Biomedical, Surgical and Dental Sciences, 'Lino Rossi' Research Center for the Study and Prevention of Unexpected Perinatal Death and SIDS, University of Milan, Milan, Italy

${ }^{2}$ Department of Oncology, Institute of Anatomic Pathology, Hospital of Rovereto (Trento), Rovereto (Trento), Italy
\end{abstract}

\section{Correspondence to}

Professor Anna Maria Lavezzi, Department of Biomedical, Surgical and Dental Sciences, 'Lino Rossi' Research Center for the Study and Prevention of Unexpected Perinatal Death and SIDS, University of Milan, Via della Commenda 19, 20122 Milano, Italy; anna.lavezzi@unimi.it

Received 18 February 2015 Revised 17 April 2015 Accepted 26 April 2015 Published Online First 13 November 2015

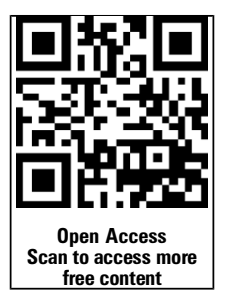

CrossMark

To cite: Lavezzi AM, Alfonsi $\mathrm{G}$, Pusiol $\mathrm{T}$, et al. J Clin Pathol 2016;69: 58-63.

\section{ABSTRACT}

Aims The nucleolus is an important cellular component involved in the biogenesis of the ribosome. This study was performed in order to validate the introduction of the argyrophilic nucleolar organiser region (AgNOR) stain technique, specific for the nucleoli detection, in neuropathological studies on sudden fetal and infant death.

Methods In a wide set of fetuses and infants, aged from 27 gestational weeks to eight postnatal months and dead from both known and unknown causes, an indepth neuropathological study usually applied at the Lino Rossi Research Center of the Milan University was implemented by the AgNOR method.

Results Peculiar abnormalities of the nucleoli, as partial or total disruption above all in Purkinje cells (PCs), were exclusively found in victims of sudden fetal and infant death, and not in controls. The observed nucleolar alterations were frequently related to nicotine absorption in pregnancy.

Conclusions We conclude that these findings represent early hallmarks of PC degeneration, contributing to the pathophysiology of sudden perinatal death.

\section{INTRODUCTION}

The nucleoli consist of nucleolar organiser regions (NORs) that are active portions of chromosomes in the nucleus involved in ribosomal synthesis. ${ }^{1}$ In humans, they are loops of DNA containing ribosomal genes (rDNA) located on the short arms of the five acrocentric chromosomes (chromosomes 13, 14, 15, 21 and 22). ${ }^{2}$ Proteins included in NORs are argyrophilic and can be easily visualised with colloidal silver methods as black dots (AgNOR proteins or AgNORs) in the cell nucleus during interphase. $^{3-5}$ Then, the features of the silver deposits allow the nucleolus to be defined and, in particular, the degree of transcriptional nucleolar activity evaluated.

Numerous studies, using AgNOR staining on histological sections from formalin-fixed, paraffinembedded tumour tissues, have reported a positive correlation between an increased size and/or number of AgNORs and the proliferative activity of neoplastic cells. Therefore, the morphology and the mean number of AgNOR dots per nucleus could reflect the tumour malignancy, and so could be used for diagnostic and prognostic purposes. ${ }^{6-8}$

The utility of AgNOR parameters has also been proven in human postmortem neurological research on depression, suicide, schizophrenia and neurodegenerative pathologies. In particular, in Parkinson's disease, a disruption and/or decreased nucleolar volume have been reported while, on the contrary, nucleolar hypertrophy has been found in Alzheimer's disease..$^{9-13}$

Nucleolar alterations, such as organisation, size and protein content changes, seem to be associated with various cellular stressors. ${ }^{14-16}$ Hypoxia, oxidants and free radicals are also known to be pathogenic stressful factors in sudden fetal and infant death (sudden intrauterine unexplained death syndrome (SIUDS) and sudden infant death syndrome (SIDS)), ${ }^{17-19}$ resulting in functional and/or morphological developmental alterations of brain centres presiding over the vital functions. Nevertheless, no reports in literature have taken into consideration AgNOR as an index of neuronal response to distress in these pathologies.

In this work, we applied the silver-staining method to make a specific identification and analysis of the nucleolus in the brain neurons of a group of victims of sudden perinatal death, already object of our prior studies, but not formerly investigated in this regard. We reconsidered a total of 43 fetuses and infants, aged from 27 gestational weeks (gw) to eight postnatal months, who had died of known or unknown causes. Our aims were, first, to obtain basic information on the nucleolar parameters in the autonomic nervous system (ANS) neurons in the different groups of the study and to evaluate their possible developmental defects in sudden perinatal and infant death, in addition to the brainstem and cerebellum morphofunctional alterations that we had already reported. ${ }^{20-24}$

Then, since high concentrations of oxidants and free radicals are contained in nicotine, the major constituent of cigarette smoke, ${ }^{25} 26$ we considered the possible correlation between AgNOR pathological changes and hypoxic stressors related to cigarette-smoke absorption in pregnancy.

\section{METHODS}

A total of 43 brains from 24 fresh antepartum stillbirths (27-39 gw, mean age $37 \mathrm{gw})$ and 19 infants aged between 1 and 8 months (mean age 3.1 months) were selected for this study on the basis of the completeness of clinical/environmental information, especially with reference to maternal lifestyle. In particular, in accordance with the aim of the study, the maternal smoking history had to be well documented (as mean number of cigarettes smoked before conception, during pregnancy and/ or after delivery, as well as possible secondhand smoke absorption).

Twenty-two mothers (51\%) admitted that they were active smokers (15 before and during 
pregnancy and six of them also after delivery), smoking a mean of 5 cigarettes per day, while 21 (49\%) declared no history of cigarette smoking. Since retrospective assessment of the mother's smoking habit, mainly performed after the death of a child, is sometimes unavoidable, the negative self-reports were verified by quantitation by gas chromatography/chemical ionisation mass spectrometry of cotinine, the main metabolite of nicotine, in hair tufts of victims $(5-10 \mathrm{mg})$, collected at autopsy for this purpose from the occipital region of the scalp. ${ }^{27}$ In two cases of mothers who denied smoking, these tests were positive, showing relevant traces of cotinine trapped in the hair shaft (by ionic bonds with keratin and melanin molecules), thus increasing the actual number of smoker mothers to 24 (56\%).

\section{Consent}

Parents of all the victims of the study provided written informed consent to autopsy.

The victims were subjected to a complete autopsy, including examination of the placental disc, umbilical cord and membranes in fetal deaths. In all cases, an in-depth histological examination of the autonomic nervous system was made, according to the protocol routinely followed by the 'Lino Rossi Research Center for the study and prevention of unexpected perinatal death and the SIDS' of Milan University, available at the website (http://users.unimi.it/centrolinorossi/en/guidelines. html).

Briefly, after fixation in $10 \%$ phosphate-buffered formalin, the brains were processed and embedded in paraffin. In particular, transverse serial sections of the brainstem (midbrain, pons, medulla oblongata) were made at intervals of 60 micron. The cerebellum was excised from the pons by dividing the peduncles. Sections at the same $60 \mu \mathrm{m}$ intervals were obtained from both the cerebellar hemispheres, including the vermis and hilum of the dentate nucleus.

For each level, from both the brainstem and cerebellum, sixseven $3-5 \mu \mathrm{m}$ sections were obtained, two of which were stained for histological examination using H\&E and KlüverBarrera stains and two for histochemical detection of AgNORs. The remaining sections were saved for further investigations and stained as deemed necessary.

The routine histological evaluation of the brainstem was focused on the locus coeruleus, the parafacial/facial complex, the superior olivary complex, the retrotrapezoid nucleus, the superior olivary nucleus, the Kölliker-Fuse nucleus, the substantia nigra in the pons/mesencephalon; on the hypoglossus, the dorsal motor vagal, the tractus solitarius, the ambiguus, the pre-Bötzinger, the inferior olivary and the arcuate nuclei in the medulla oblongata. In the cerebellar sections, the dentate, the fastigial, the globose, the emboliform nuclei and the cortex layers were analysed.

In 27 cases, after the in-depth autoptic examination, the death remained totally unexplained. A diagnosis of 'SIUDS' was therefore made for 15 fetuses who died suddenly after the 27 th gestational week before complete expulsion or retraction from the mother, and a diagnosis of 'SIDS' for 12 infants who died within the first 8 months of life. In the remaining 16 cases, nine stillbirths and seven infants, a precise cause of death was formulated at autopsy. These cases were regarded as 'controls'.

Table 1 summarises the study cases, indicating the sex distribution, range of ages, death diagnoses and maternal smoking habit.

\section{Silver nitrate method for AgNOR protein sites}

According to the Bancroft and Gamble indications, ${ }^{28}$ the sections selected for AgNOR staining were deparaffinised in xylene, then hydrated through descending alcohol concentrations to distilled water. After rinsing in distilled water, the tissues were incubated for $45 \mathrm{~min}$ at room temperature in the dark, in freshly prepared working solution, consisted of two parts of a $50 \%$ silver nitrate solution and one part of $2 \%$ gelatin in $1 \%$ formic acid solution. Distilled water was used for the preparation of both these solutions.

The AgNOR-stained sections were examined under a light microscope attached to a computerised image analysis system (Nikon Eclipse E800 microscope and Nikon digital camera DXM1200). The slides were, first, scanned with $\times 4, \times 10$ and $\times 40$ lenses, then the AgNOR examination was performed under $\times 100$ magnification using oil immersion. Eyepieces $(\times 10)$ provided a maximum magnification of 1000 . The condenser was, in turn, adjusted to change the light intensity, so allowing visualisation of the refracting AgNOR components.

Following the above reported protocol, AgNOR sites were visualised as intranuclear black/brown dots of variable size on a pale yellow background. Glial cells and interneurons, identified on the basis of their smaller size, poor cytoplasm and darker nuclear outline, were excluded from the analysis.

\section{Scoring of AgNOR staining results}

Each case was scored according to the presence of AgNOR staining. In detail, in each silver nitrate preparation from brainstem and cerebellum, we, first, counted the total number of neurons showing positive AgNOR nuclear granules out of 150-200 randomly selected neurons, quantifying the final results according to a 'general score', as follows:

$0=$ no AgNOR staining

$1=$ percentage of positive AgNOR neurons $<30 \%$

$2=$ percentage of positive AgNOR neurons $\geq 30 \%-60 \%$

$3=$ percentage of positive AgNOR neurons $>60 \%-80 \%$

Table 1 Case profiles of the study

\begin{tabular}{|c|c|c|c|c|c|}
\hline \multirow[b]{2}{*}{ Victims ( $n=43$ ) } & \multirow[b]{2}{*}{ Age (range) } & \multicolumn{2}{|l|}{ Sex } & \multicolumn{2}{|l|}{ Death diagnosis } \\
\hline & & $\mathbf{M}$ & $F$ & $\begin{array}{l}\text { Explained deaths Controls } \\
(n=16)\end{array}$ & $\begin{array}{l}\text { Unexplained deaths } \\
(n=27)\end{array}$ \\
\hline \multirow[t]{2}{*}{ Fetuses $(n=24)$} & $27-39 \mathrm{gw}$ & 10 & 14 & $\begin{array}{l}\text { Necrotising chorioamnionitis }(n=5) \\
\text { Congenital heart disease }(n=4)\end{array}$ & \\
\hline & & & & Smoking mothers $(n=2)$ & Smoking mothers $(n=12)$ \\
\hline \multirow[t]{2}{*}{ Infants $(n=19)$} & $1-8$ months & 10 & 9 & Pneumonia $(n=4)$ & $\operatorname{SIDS}(n=12)$ \\
\hline & & & & Smoking mothers $(n=1)$ & Smoking mothers $(n=9)$ \\
\hline
\end{tabular}


$4=$ percentage of positive AgNOR neurons $>80 \%$

The same rating scale was used for the evaluation of the neurons exhibiting nucleolar AgNOR granules within each of the above-mentioned brainstem and cerebellum specific nuclei and/or structures ('specific score').

\section{Statistical analysis}

Histological and histochemical observations were carried out blindly by two independent pathologists. Comparison of results was performed employing K-statistics (K Index, KI) to evaluate the interobserver reproducibility. The Landis and Koch system ${ }^{29}$ of $\mathrm{K}$ interpretation was used, where $0-0.2$ is slight agreement, $0.21-0.40$ indicates fair agreement, $0.41-0.60$ moderate agreement, $0.61-0.80$ strong or substantial agreement and 0.81-1.00 indicates very strong or almost perfect agreement (a value of 1.0 being perfect agreement). The application of this method revealed a very satisfactory KI $(0.88)$.

Analysis of variance was applied to evaluate if there were statistically significant differences between groups of victims, and verifying, for the validity of the results, that no assumption required from this test ${ }^{30}$ has been violated. Statistical calculations were carried out with SPSS statistical software (V.12.0). $\mathrm{p}$ Values $<0.05$ were accepted as statistically significant.

\section{RESULTS}

\section{AgNOR findings in controls}

At light microscopy, the nucleoli appeared in the appropriately stained sections of brainstem and cerebellum as highly refracting rounded formations, mostly with an eccentric location in pale yellow stained nuclei, surrounded by variably sized and irregularly shaped black/brown dots of condensed heterochromatin (heterochromatin-associated nucleolus), joined together by thin filaments to form a ring 'necklace-like' organisation (figure 1). We considered every AgNOR dot as a 'nucleolar transcription unit' (NTU). The NTUs were visible in almost all the examined neurons (150-200 per section) for each case ('general score' $=4$; mean percentage of neurons showing AgNOR positivity: 89\% in the fetal control group and $86 \%$ in infant controls) (figure 2). The percentage of AgNOR-expressing neurons was high also within each specific structure considered for the histological diagnosis ('specific score' for all=3/4) (figure 3).

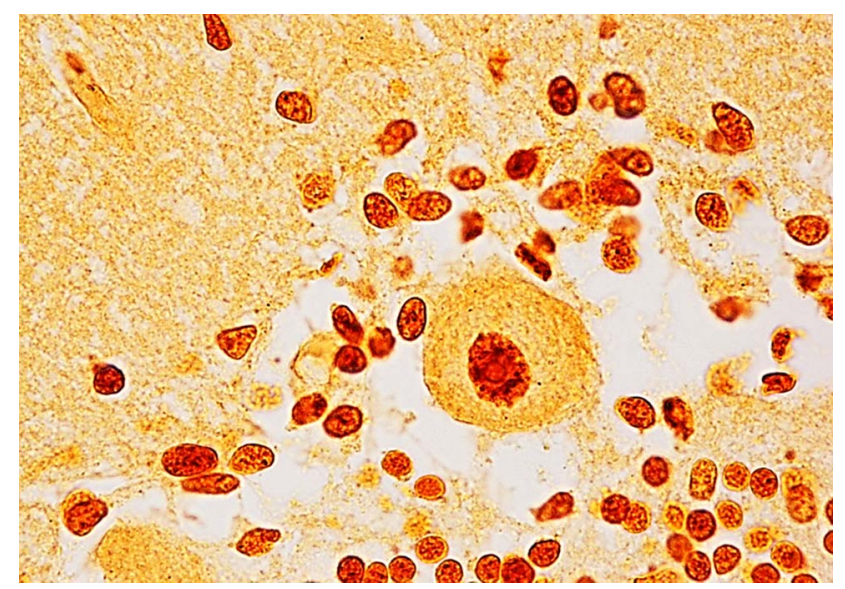

Figure 1 Typical necklace-like appearance of the nucleolar organisation around a refracting rounded formation in a Purkinje cell (PC) of a 3-month-old infant of the control group. Argyrophilic nucleolar organiser region (AgNOR) staining; magnification $\times 100$.

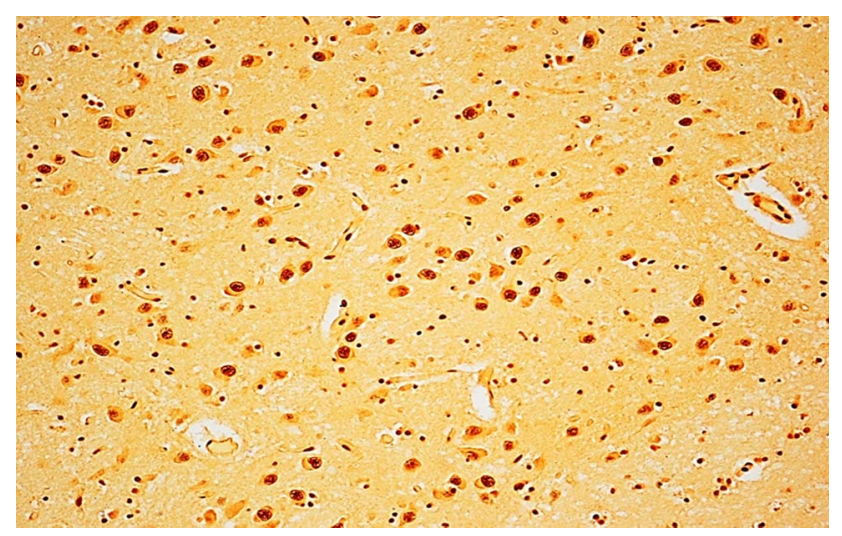

Figure 2 Argyrophilic nucleolar organiser region (AgNOR)-positive neurons in a pontine histological section of a 38-week human fetus of the control group. Example of high 'general score' (explanation in the 'Methods' section). AgNOR staining; magnification $\times 20$.

\section{AgNOR findings in SIUDS/SIDS}

In about half of the victims of sudden death (52\%), the 'general score' of the AgNOR expression did not differ from that of agematched controls. However, a noteworthy finding was related to a 'specific score' detected in the cerebellar cortex of nine SIUDS and four SIDS cases. Surprisingly, in fact, intermixed with several PCs showing a swollen, shrunken morphology and lacking both nucleus and arborisation, we observed the total absence of the typical nucleolar structure and AgNOR staining, or sometimes a nucleolar disruption with weak evidence of AgNOR positivity, in almost all the morphologically undamaged cells $(81 \%)$ ('specific score' for PCs=0/1) (figure 4). In nine of the same cases with nucleolar disorganisation (seven SIUDS and two SIDS), poor AgNOR dots were detected prevalently in the inferior olivary nucleus (ION) and in the hypoglossus nucleus $(\mathrm{HN})$ in the medulla oblongata, and in the locus coeruleus (LC) in the rostral pons, but with lower incidences $(36 \%$ and $21 \%$, respectively; 'specific score' for ION, HN and LC=1).

In all, AgNOR patterns were significantly different in SIUDS/ SIDS cases versus controls $(48 \%$ vs $=0 \%, \mathrm{p}<0.01)$.

\section{Correlation of AgNOR findings with smoke exposure}

Eighteen of the 24 smokers were mothers of a victim of sudden death (10 SIUDS and 8 SIDS). A significant correlation was found between a negative or weak expression of AgNOR in PCs and maternal smoking $(\mathrm{p}<0.01)$. In fact, 11 cases, seven of the nine SIUDS and all the four SIDS cases with an altered expression of AgNOR in PCs, had a smoker mother.

\section{Additional results on brainstem and cerebellum}

These AgNOR analyses complemented the brainstem and cerebellum alterations, highlighted in this case series, in our previous works. These findings included hypoplasia/agenesis of the arcuate, the pre-Bötzinger, the parafacial and serotonergic raphé nuclei in the brainstem and hypoplasia of the dentate nucleus and delayed cerebellar cortex maturation in the cerebellum.

\section{DISCUSSION}

To our knowledge, the present study is the first to have been performed on argyrophilic nucleolar proteins expression in the human nervous system in perinatal age. AgNOR staining, extensively used in the past by cancer pathologists to assess cell proliferation, ${ }^{6-8}$ has here been exploited as a co-stain to evaluate the possible presence of nucleolar alterations in SIUDS/SIDS cases. 
Figure 3 Argyrophilic nucleolar organiser region (AgNOR)-positive neurons in the hypoglossus nucleus (HN). Histological section of medulla oblongata of a 36-week human fetus of the control group. Example of high 'specific score' (explanation in the 'Methods' section). The framed area in $(A)$ is represented at higher magnification in (B). AgNOR staining; magnification $(A) \times 10$; $(B) \times 20$.
A

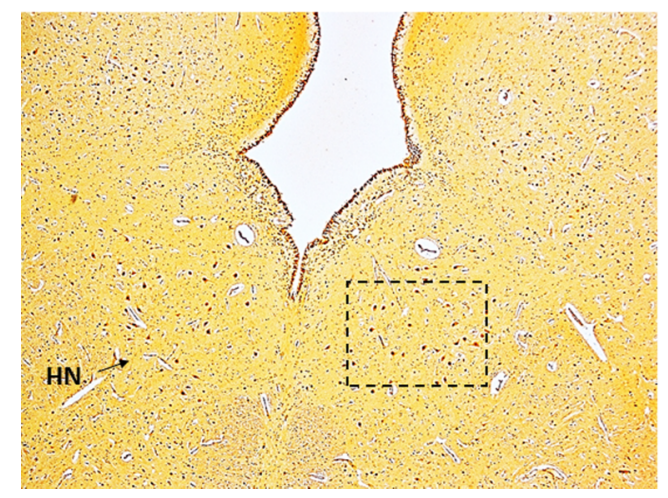

B

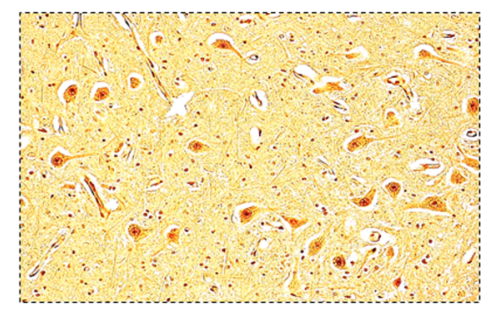

Nucleoli are known to be sites of ribosome-subunit production. However, multiple investigations, including large-scale proteomic studies, ${ }^{31} 32$ have disclosed additional roles for nucleoli in important cellular processes, such as cell-cycle control and primary response to cellular stressors.

Indeed, a correlation has been demonstrated between the nucleolar rDNA arrangement and cell-cycle phases. ${ }^{33}{ }^{34}$ In fact, the rDNA results were heterogeneously distributed during the G1, S and G2 phases (ie, interphase), with alternate sites of clustered genes (nucleolar granular portion) and genes in a more extended arrangement (nucleolar fibrillar portion), together configuring a necklace-like structure. The number of granules, 4-6 in G1 (1.8-2 $\mu \mathrm{m}$ diameter), increases during the $S$ phase, but they are smaller $(7-12 ; 0.5 \mu \mathrm{m}$ diameter), and progressively decreases in G2. The nucleolus disappears at the beginning of mitosis, and reassembly occurs during telophase and the early G1 phase.

In humans, nucleolar AgNOR granules can be visualised during interphase at the short arms of the acrocentric chromosome. ${ }^{2}$ Even if their fine structure can be clearly disclosed only by electron microscopic investigations, ${ }^{35} 36$ we can consider every nucleolar dot visible at light microscope, according to Haaf et $a l,{ }^{37}$ as a 'NTU'.

As regards their involvement in stress responses, it has been demonstrated that the dynamic nature of the nucleoli is enhanced under different injurious conditions. Stressors such as viral infections, ultraviolet (UV) irradiation, drug absorption and hypoxia cause, as a primary cellular reaction, dramatic changes in the nucleolar organisation in terms of heterochromatin aggregates and rDNA repeats. ${ }^{14-16}$

Morphometric experimental studies on silver-stained preparations of the CNS demonstrated a direct correlation between the features of the nucleolus and the neuronal activity. ${ }^{38-40}$ Thus, changes in the size and number of NTU in nervous cells may represent a valuable index of neuronal damage.

In this study, we observed a significantly decreased number of NTU in the cerebellar PCs in SIUDS/SIDS victims versus controls, suggestive of a decreased rDNA transcriptional activity and of hypofunction of these cells, very likely a consequence of exposure to nicotine during gestation. In fact, a significant correlation was highlighted between altered nucleoli manifestations in PCs and maternal smoking.
A
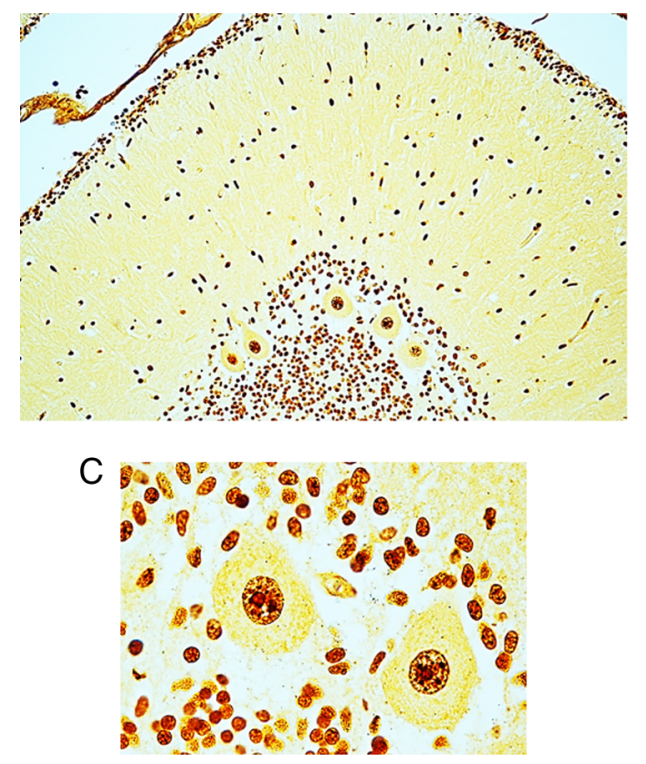

B

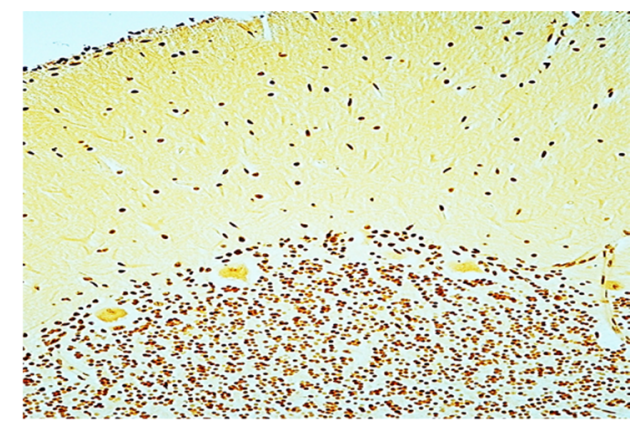

D

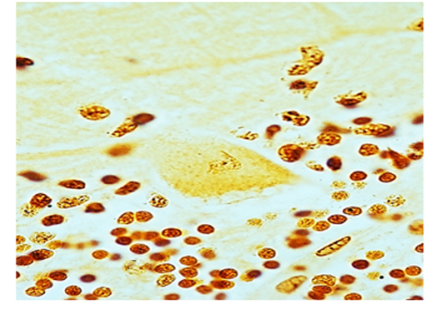

Figure 4 (A) Argyrophilic nucleolar organiser region (AgNOR)-positive Purkinje cells (PCs) in a 2-month-old control case presented at greater magnification in (C). (B) AgNOR-negative PCs in a SIDS case died at 3 months. (D) One of these cells at greater magnification. AgNOR staining; magnification $(A)$ and $(B) \times 20$; (C) and (D) $\times 100$. 
The cerebellar PCs are among the largest cells in the CNS and constitute the only output elements of the cerebellar cortex. They are characterised by one of the most sophisticated dendritic trees, which allows them to integrate signals from both the cerebellar and extracerebellar circuitry, so playing a key role in the coordination of the autonomic functions. ${ }^{41-44}$

It is well known that the protracted development of the cerebellar cortex, that ends only around 1 year of age, makes this structure a target for a broad spectrum of extrinsic injuries, such as cigarette smoke, air pollution, ionising radiations, drugs and alcohol. ${ }^{45-47}$ In particular, the PCs are very vulnerable to oxidative stress, hypoxia and to other genotoxic agents that induce DNA damage, leading to acquired disorders during their development. Accordingly, the PC nucleolar alterations observed in this study can be considered as the first cellular reaction to hypoxic conditions and the initial stage of degenerative processes culminating in the shrunken morphology with nuclear disruption, sometimes visible in both SIUDS and SIDS cases.

Therefore, alterations of the nucleolus in PCs still morphologically intact represent an early primary step in the neurodegeneration pathway. As the nucleolus is involved in the ribosome biogenesis, its disruption leads to a severe dysfunction of protein synthesis and ultimately to neuronal degeneration of these cells that play a major role in the control of the autonomic functions.

\section{CONCLUSIONS}

The findings herein reported suggest that the nucleolus plays a critical role, prevalently in human PCs development, quickly responding to harmful agents by changes in their structural organisation.

We believe that application of the AgNOR method merits particular attention in neuropathological studies on SIUDS and SIDS. The changes in PC AgNOR parameters observed in these syndromes and not in controls could be, in fact, a useful diagnostic tool. Further cases need to be investigated in order to exactly understand how nucleolar damage in PCs can contribute to the pathophysiology of SIUDS and SIDS.

\section{Take home messages}

- This study introduces for the first time the argyrophilic nucleolar organiser region (AgNOR) histochemical staining as a useful tool in neuropathological studies, above all, to identify the early neuronal alterations in sudden unexplained perinatal deaths.

- These alterations are represented by different grades of nucleolar disruption in the cerebellar Purkinje cells (PCS), frequently related to nicotine absorption in pregnancy.

- Given the important role of the PCs in the autonomic control, the findings here reported represent early hallmarks of neuronal impairment contributing to the pathogenesis of sudden perinatal death.

\section{Handling editor Cheok Soon Lee}

Acknowledgements The authors thank Ms Mary Victoria Candace Pragnell for English revision of this manuscript. This study was supported by the Italian Health Ministry in accordance with the Law 31/2006 'Regulations for Diagnostic Post Mortem Investigation in Victims of Sudden Infant Death Syndrome (SIDS) and Unexpected Fetal Death', and by the Convention with the ASL-Provincia autonoma of Trento.
Contributors AML planned the study, analysed the data and wrote the manuscript with collaborative input and extensive discussion with TP and LM. GA performed the histological procedures and participated in the interpretation of the results. All authors read and approved the final manuscript.

Competing interests None declared.

Patient consent Obtained.

Ethics approval Milan University Lino Rossi Research Center Institutional Review Board.

Provenance and peer review Not commissioned; externally peer reviewed.

Open Access This is an Open Access article distributed in accordance with the Creative Commons Attribution Non Commercial (CC BY-NC 4.0) license, which permits others to distribute, remix, adapt, build upon this work non-commercially, and license their derivative works on different terms, provided the original work is properly cited and the use is non-commercial. See: http://creativecommons.org/ licenses/by-nc/4.0/

\section{REFERENCES}

1 Schwarzacher $\mathrm{HG}$, Wachtler $\mathrm{F}$. The functional significance of nucleolar structures. Ann Genet 1991;34:151-60. Review.

2 Lee $W$, Kim Y, Lee KY, et al. AgNOR of human interphase cells in relation to acrocentric chromosomes. Cancer Genet Cytogenet 1999;113:14-18.

3 Aubele M, Biesterfeld S, Derenzini M, et al. Guidelines of AgNOR quantitation. Committee on AgNOR Quantitation within the European Society of Pathology. Zentralb/ Pathol 1994;140:107-8.

4 Howell WM. Selective staining of nucleolus organizer regions (NORs). In: Busch $\mathrm{H}_{\text {, }}$ Rothblum L, eds, The cell nucleus. New York: Academic Press, 1982:89-143.

5 Trerè D. AgNOR staining and quantification. Micron 2000;31:127-31.

6 Pich A, Chiusa L, Margaria E. Role of the argyrophilic nucleolar organizer regions in tumor detection and prognosis. Cancer Detect Prev 1995;19:282-91.

7 Derenzini M, Farabegoli F, Trerè D. Relationship between interphase AgNOR distribution and nucleolar size in cancer cells. Histochem J 1992;24:951-6.

8 Derenzini M, Sirri V, Treré D. Nucleolar organizer regions in tumor cells. Cancer J 1994:7:71-7.

9 Gos T, Krell D, Brisch R, et al. The changes in AgNOR parameters of dorsal raphe nucleus neurons are related to suicide. Leg Med (Tokyo) 2007;9:251-7.

10 Gos T, Krell D, Bielau H, et al. Demonstration of disturbed activity of the lateral amygdaloid nucleus projection neurons in depressed patients by the AgNOR staining method. J Affect Disord 2010;126:402-10.

11 Rieker C, Engblom D, Kreiner G, et al. Nucleolar disruption in dopaminergic neurons leads to oxidative damage and parkinsonism through repression of mammalian target of rapamycin signaling. J Neurosci 2011;31:453-60.

12 Lu W, Tang H, Mi R, et al. Research on nucleolar organizer regions of hippocampal neuron in Alzheimer's disease. Chin Med J 1998;111:282-4.

13 lacono D, Resnick SM, O'Brien R, et al. Mild cognitive impairment and asymptomatic Alzheimer disease subjects: equivalent $\beta$-amyloid and tau loads with divergent cognitive outcomes. J Neuropathol Exp Neurol 2014;73:295-304.

14 Mayer C, Grummt I. Cellular stress and nucleolar function. Cell Cycle 2005; $4: 1036-8$

15 Boulon S, Westman BJ, Hutten S, et al. The nucleolus under stress. Mol Cell 2010;40:216-27

16 Mayer $\mathrm{C}$, Bierhoff $\mathrm{H}, \mathrm{Grummt} \mathrm{I}$. The nucleolus as a stress sensor: JNK2 inactivates the transcription factor TIF-IA and down-regulates rRNA synthesis. Genes Dev 2005; 19:933-41.

17 Baba L, McGrath JM. Oxygen free radicals: effects in the newborn period. Adv Neonatal Care 2008:8:256-64.

18 Dick A, Ford R. Cholinergic and oxidative stress mechanisms in sudden infant death syndrome. Acta Paediatr 2009;98:1768-75.

19 Huggle $\mathrm{S}$, Hunsaker JC, Coyne CM, et al. Oxidative stress in sudden infant death syndrome. J Child Neurol 1996;11:433-8.

20 Lavezzi AM, Ottaviani G, Mauri M, et al. Alterations of biological features of the cerebellum in sudden perinatal and infant death. Curr Mol Med 2006;6:429-35.

21 Lavezzi AM, Ottaviani G, Ballabio GM, et al. Preliminary study on the cytoarchitecture of the human parabrachial/Kölliker-Fuse complex with reference to sudden infant death syndrome and sudden intrauterine unexplained death. Pediatr Dev Pathol 2004;72:171-9.

22 Lavezzi AM, Matturri L. Functional neuroanatomy of the human pre-Bötzinger complex with particular reference to sudden unexplained perinatal and infant death. Neuropathology 2008;28:10-16.

23 Lavezzi AM, Matturri L. Hypoplasia of the parafacial/facial complex: a very frequent finding in sudden unexplained fetal death. Open Neurosci J 2008;2:1-5.

24 Matturri L, Lavezzi AM. Unexplained stillbirth versus SIDS: common congenital diseases of the autonomic nervous system-pathology and nosology. Early Hum Dev 2011;87:209-15

25 Pryor WA, Stone K. Oxidants in cigarette smoke. Radicals, hydrogen peroxide peroxynitrate and peroxynitrite. Ann NY Acad Sci 1993;686:12-27. 
26 Reilly M, Delanty N, Lawson JA, et al. Modulation of oxidant stress in vivo in chronic cigarette smokers. Circulation 1995;94:9-25.

27 Jacqz-Aigrain E, Zhang D, Maillard G, et al. Maternal smoking during pregnancy and nicotine and cotinine concentrations in maternal and neonatal hair. BJOG 2002;109:909-11.

28 Bancroft JD, Gamble M. Theory and practice of histological techniques. 5th edn. Philadelphia, PA: Churchill Livingstone Elsevier, 2002;350-1.

29 Landis RJ, Koch GG. The measurement of observer agreement for categorical data. Biometrics 1977;33:159-74.

30 Beri GC. Analysis of variance. In: Business statistics. 3rd edn. New Delhi, India: Tata McGraw Hill, 2010:408.

31 Andersen JS, Lam YW, Leung AK, et al. Nucleolar proteome dynamics. Nature 2005;433:77-83.

32 Scherl A, Couté Y, Déon C, et al. Functional proteomic analysis of human nucleolus. Mol Biol Cell 2002;13:4100-9.

33 Junera HR, Masson C, Geraud G, et al. The three-dimensional organization of ribosomal genes and the architecture of the nucleoli vary with $\mathrm{G} 1, \mathrm{~S}$ and $\mathrm{G} 2$ phases. J Cell Sci 1995; 108:3427-41.

34 Hernandez-Verdun D. Assembly and disassembly of the nucleolus during the cell cycle. Nucleus 2011;2:189-94.

35 Derenzini M, Thiry M, Goessens G. Ultrastructural cytochemistry of the mammalian cell nucleolus. J Histochem Cytochem 1990;38:1237-56.

36 Zatsepina 0, Hozak O, Babadjanyan P, et al. Quantitative ultrastructural study of nucleolus-organizing regions at some stages of the cell cycle (G0 period, G2 period, mitosis). Biol Cell 1988;62:211-18.

37 Haaf T, Hayman DL, Schmid M. Quantitative determination of rDNA transcription units in vertebrate cells. Exp Cell Res 1991;193:78-86.
38 Mennel HD, Müller I. Morphometric investigation on nuclear and nucleolar arrangement and AgNOR content in the rat hippocampus under normal and ischemic conditions. Exp Toxicol Pathol 1994; 46:491-501.

39 Healy-Stoffel M, Ahmad SO, Stanford JA, et al. A novel use of combined tyrosine hydroxylase and silver nucleolar staining to determine the effects of a unilateral intrastriatal 6-hydroxydopamine lesion in the substantia nigra: a stereological study. J Neurosci Methods 2012;210:187-94.

40 Vázquez Nin GH, Echeverría OM, Zavala G, et al. Relations between nucleolar morphometric parameters and pre-rRNA synthesis in animal and plant cells. Acta Anat (Basel) 1986;126:141-6.

41 Ito M. The cerebellum and neuronal control. New York: Raven Press, 1984.

42 Lavezzi AM, Ottaviani G, Terni L, et al. Histological and biological developmental characterization of the human cerebellar cortex. Int I Dev Neurosci 2006:24:365-71.

43 Sotelo C, Rossi F. Purkinje cell migration and differentiation. In: Manto M, Gruol D, Schmamann J, et al., eds. Handbook of cerebellum and cerebellar disorders. New York: Springer, 2011.

44 McKay BE, Turner RW. Physiological and morphological development of the rat cerebellar Purkinje cell. J Physiol 2005;567:829-50.

45 Fonnum F, Lock EA. Cerebellum as a target for toxic substances. Toxicol Lett 2000;112-113:9-16.

46 Lewandowska E, Stecpień T, Wierzba-Bobrowicz T, et al. Alcohol-induced changes in the developing cerebellum. Ultrastructural and quantitative analysis of neurons in the cerebellar cortex. Folia Neuropathol 2012;50:397-406.

47 Hausmann R, Seidl S, Betz P. Hypoxic changes in Purkinje cells of the human cerebellum. Int J Legal Med 2007;121:175-83. 